Supporting Information

\title{
Optimizing the Performance of Perovskite Nanocrystal LEDs Utilizing Cobalt Doping on ZnO Electron Transport Layer
}

\author{
Chengyuan Tang,, Xinyu Shen,,a,* Xiufeng Wu,a Yuan Zhong,a Junhua Hu, ${ }^{b}$ \\ Min Lu, ${ }^{a}$ Zhennan Wu, ${ }^{a}$ Yu Zhang, ${ }^{a}$ William W. Yu, ${ }^{c, *}$ Xue Bai a,**
}

a State Key Laboratory of Integrated Optoelectronics and College of Electronic Science and Engineering, Jilin University, Changchun 130012, China

b Key Laboratory of Materials Physics of Ministry of Education Department of Physics and Engineering, Zhengzhou University, Zhengzhou 450052, China

c Department of Chemistry and Physics, Louisiana State University, Shreveport, Louisiana 71115, USA

* Corresponding authors.

E-mails: shen xinyu1993@163.com (X. Shen), wyu6000@gmail.com (W. W. Yu), baix@jlu.edu.cn (X. Bai) 


\section{EXPERIMENTAL SECTION}

Materials. Oleylamine (OLA, 70\%), zinc acetate dihydrate $\left(\mathrm{C}_{4} \mathrm{H}_{6} \mathrm{O}_{4} \mathrm{Zn} \cdot 2 \mathrm{H}_{2} \mathrm{O}\right)$ and cobalt (II) acetate tetrahydrate $\left(\mathrm{C}_{4} \mathrm{H}_{6} \mathrm{O}_{4} \mathrm{Co}_{2} \cdot 4 \mathrm{H}_{2} \mathrm{O}\right)$ were bought from Aladdin. Dimethyl sulfoxide (DMSO) was purchased from Tianjin Fuyu Fine Chemical Co., Ltd. Tetramethylammonium hydroxide pentahydrate (TMAH, 98\%) was got from Alfa Aesar. Ethanol was purchased from Tianjin Guangfu Technology Development Co., Ltd. Lead (II) iodide ( $\mathrm{PbI}_{2}$, 99.999\%), octadecene (ODE, 90\%) and oleic acid (OA, 90\%) were purchased from Sigma-Aldrich. $\mathrm{Cs}_{2} \mathrm{CO}_{3}$ (99.9\%) was got from J\&K Chemicals. These chemicals were used without any purification.

Synthesis of ZnO and CZO NCs. The preparation of ZnO NCs was based on the published method. $\mathrm{C}_{4} \mathrm{H}_{6} \mathrm{O}_{4} \mathrm{Zn} \cdot 2 \mathrm{H}_{2} \mathrm{O}(0.6585 \mathrm{~g}, 3 \mathrm{mmol})$ and DMSO $(30 \mathrm{~mL})$ were loaded into a $100 \mathrm{~mL}$ 3-neck flask and stirred in vacuum until the mixture became clear. Then, TMAH (0.9062 g, $5 \mathrm{mmol})$ was dissolved in $10 \mathrm{~mL}$ ethanol, and the solution was dropwise added into DMSO solution at room temperature and the mixture reacted for $1 \mathrm{~h}$. For the purification, excess acetone was added into the reaction solution and centrifuged at $5000 \mathrm{rpm}$ for $10 \mathrm{~min}$. The supernatant was discarded and the precipitate was dispersed in ethanol $(2 \mathrm{~mL})$ by oscillating. Using the same method, $\mathrm{Zn}_{1-\mathrm{x}} \mathrm{Co}_{\mathrm{x}} \mathrm{O}$ ( $\mathrm{x}=2.2 \%, 4.5 \%, 6.6 \%$, and $\left.8.8 \%\right)$ NCs were prepared by adjusting the molar concentration of cationic $\left(\mathrm{Zn}^{2+}\right.$ and $\left.\mathrm{Co}^{2+}\right)$ precursors with other parameters fixed.

Synthesis of CsPbI 3 NCs. Cesium oleate was firstly prepared. ODE (30 mL), $\mathrm{Cs}_{2} \mathrm{CO}_{3}(0.814 \mathrm{~g}, 2.5 \mathrm{mmol})$ and $\mathrm{OA}(2.5 \mathrm{~mL})$ were added into a 3-neck flask and stirred under vacuum at $120^{\circ} \mathrm{C}$. After $1 \mathrm{~h}$, the mixture was heated to $150{ }^{\circ} \mathrm{C}$ under $\mathrm{N}_{2}$ until it became clear. The next step was to synthesize the NCs. $\mathrm{PbI}_{2}(0.173 \mathrm{~g}, 0.376 \mathrm{mmol})$ and ODE $(10 \mathrm{~mL})$ were mixed in a $50 \mathrm{~mL} 3$-neck flask and stirred under vacuum at $120{ }^{\circ} \mathrm{C}$ for $1 \mathrm{~h}$, then OLA $(1 \mathrm{~mL})$ and OA $(1 \mathrm{~mL})$ were injected under $\mathrm{N}_{2}$. After the mixture became clear, the temperature was increased to $170{ }^{\circ} \mathrm{C}$ and cesium oleate $(0.8 \mathrm{~mL}$, $0.123 \mathrm{mmol}$, preheated to $100^{\circ} \mathrm{C}$ ) was quickly injected. After $5 \mathrm{~s}$, the solution was immediately cooled down to room temperature by an ice water bath. The following was purification, the $\mathrm{CsPbI}_{3} \mathrm{NCs}_{\text {was }}$ purified by centrifuging at $5000 \mathrm{rpm}$ for $10 \mathrm{~min}$. After centrifugation, the supernatant was discarded and the precipitate was dispersed in toluene by oscillating.

LED Fabrication. Indium tin oxide (ITO) substrates were cleaned by using 
detergent, deionized water, ethanol, chloroform, acetone, and isopropanol with ultrasonic agitation and then by UV-ozone treatment for $10 \mathrm{~min}$. ZnO or CZO NCs solution (50 mg mL-1) was spin-coated onto the ITO substrate at $1000 \mathrm{rpm}$ for $30 \mathrm{~s}$ and annealed in air at $200{ }^{\circ} \mathrm{C}$ for $10 \mathrm{~min}$. Then, the substrate was transferred into a $\mathrm{N}_{2}$ glove-box. The polyethyleneimine (PEI) solution (dissolved in 2-methoxyethanol at $0.2 \%$ mass ratio) was spin coated onto the $\mathrm{ZnO}$ or CZO film at a speed of $3000 \mathrm{rpm}$ and annealed at $125^{\circ} \mathrm{C}$ for $10 \mathrm{~min}$. $\mathrm{CsPbI}_{3}$ emissive layer $\left(20 \mathrm{mg} \mathrm{mL}^{-1}\right)$ was spin cast at $1000 \mathrm{rpm}$ for 50 s. 4,4',4"-tris(carbazol-9-yl)-triphenylamine (TCTA), $\mathrm{MoO}_{3}$ and $\mathrm{Ag}$ were sequentially deposited by thermal evaporation in a vacuum deposition chamber $\left(1 \times 10^{-7}\right.$ Torr $)$.

Electron-only Device Fabrication. Fabrication of Device with structure of ITO/ZnO or CZO/Ag. Cleaned ITO substrates were treated by UV-ozone for $10 \mathrm{~min}$. $\mathrm{ZnO}$ or CZO NCs solution (50 mg mL-1) was spin-coated onto the ITO glass at 1000 $\mathrm{rpm}$ for $30 \mathrm{~s}$ and annealed in air at $200{ }^{\circ} \mathrm{C}$ for $10 \mathrm{~min}$. Then, the substrate was transferred into a $\mathrm{N}_{2}$ glove-box. Ag was sequentially deposited by thermal evaporation in a vacuum deposition chamber $\left(1 \times 10^{-7}\right.$ Torr $)$. Fabrication of Device with structure of ITO/ZnO or $\mathrm{CZO} / \mathrm{CsPbI}_{3} / \mathrm{Ag}$. Cleaned ITO substrates were treated by UV-ozone for $10 \mathrm{~min}$. $\mathrm{ZnO}$ or CZO NC solution (50 $\mathrm{mg} \mathrm{mL}^{-1}$ ) was spin-coated onto the ITO glass at $1000 \mathrm{rpm}$ for $30 \mathrm{~s}$ and annealed in air at $200{ }^{\circ} \mathrm{C}$ for $10 \mathrm{~min}$. Then, the substrate was transferred into a $\mathrm{N}_{2}$ glove-box. $\mathrm{CsPbI}_{3}$ emissive layer $\left(20 \mathrm{mg} \mathrm{mL}^{-1}\right)$ was spin cast at $1000 \mathrm{rpm}$ for $50 \mathrm{~s}$. Ag was deposited by thermal evaporation in a vacuum deposition chamber $\left(1 \times 10^{-7}\right.$ Torr $)$.

Hole-only Device Fabrication. Cleaned ITO substrates were treated by UVozone for $10 \mathrm{~min}$. PEDOT:PSS (4083) was spin-coated onto the ITO glass at $3000 \mathrm{rpm}$ for $1 \mathrm{~min}$ and annealed in air at $150{ }^{\circ} \mathrm{C}$ for $15 \mathrm{~min}$. $\mathrm{CsPbI}_{3}$ emissive layer $\left(20 \mathrm{mg} \mathrm{mL}^{-}\right.$ 1) was spin cast at $1000 \mathrm{rpm}$ for $50 \mathrm{~s}$. TCTA, $\mathrm{MoO}_{3}$ and $\mathrm{Ag}$ were sequentially deposited by thermal evaporation in a vacuum deposition chamber $\left(1 \times 10^{-7}\right.$ Torr $)$.

Characterizations. XRD patterns were acquired on a Bruker SMART-CCD diffractometer $(\mathrm{Cu} \mathrm{Ka}, \lambda=1.5406 \AA)$. Inductively coupled plasma mass-spectrometry (ICP-MS) was obtained on a Thermo iCAO Qc. Transmission electron microscopy (TEM) images were obtained on a PEI Tecnai F20 microscope. X-ray photoelectron spectroscopy (XPS) was carried out on an ESCALAB250 spectrometer. The AFM images were acquired using a VEECO DICPII microscope. Absorption spectra were 
measured by Shimadzu UV-2550 spectrophotometer. The photoluminescence spectra of $\mathrm{CsPbI}_{3}$ and the electroluminescence spectra of LEDs were measure by Ocean Optics spectrometer. The UPS pattern of film samples were collected on a PREVAC system. Time-resolved PL lifetime measurements were obtained on a time-correlated singlephoton counting (TCSPC) lifetime spectroscopy system with a picosecond pulsed diode laser (EPL-365 nm) as the single wavelength excitation light source. The MottSchottky (M-S) plots were measured by PARSTAT 2273 Electrochemical Workstation in the frequency range of $10^{5} \mathrm{~Hz}$ under $1.5 \mathrm{~V}$ bias. The J-V-L characteristics of the LEDs were performed with a Keithley 2612B source meter and a PhotoResearch Spectra Scan spectrometer PR 655. 


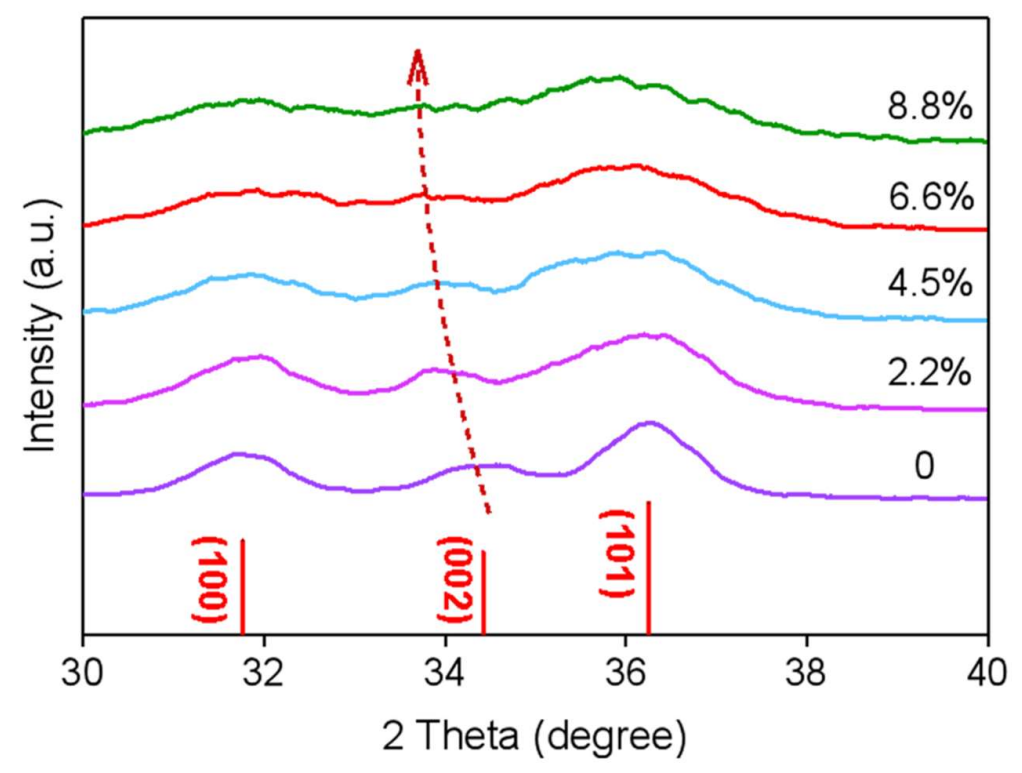

Figure S1. Enlarged XRD data at range of $30-40^{\circ}$.
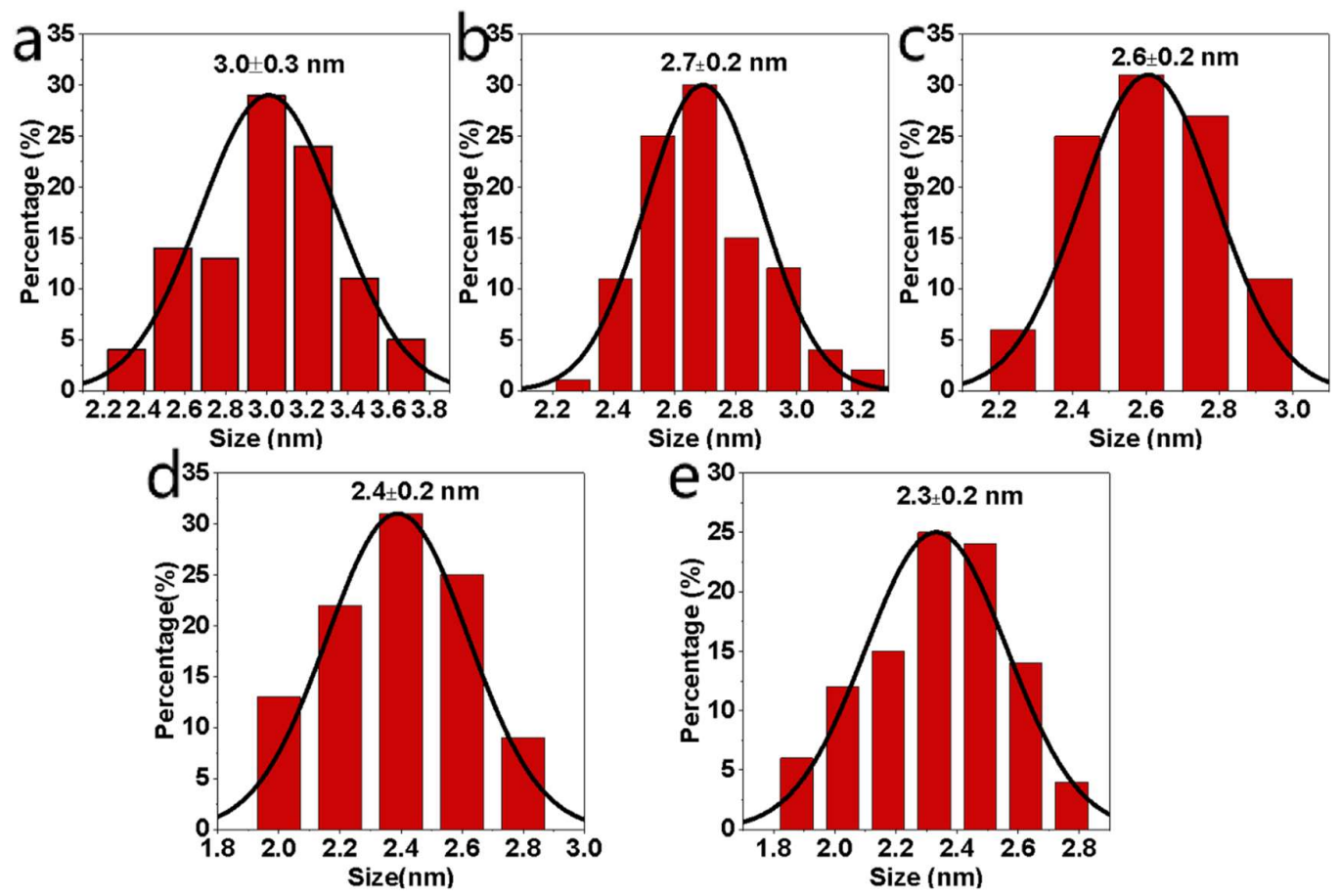

Figure S2. Size distributions of the Co doped $\mathrm{ZnO}$ NCs synthesized with Co molar percentages of: (a) 0 , (b) $2.2 \%$, (c) $4.5 \%$, (d) $6.6 \%$ and (e) $8.8 \%$. 


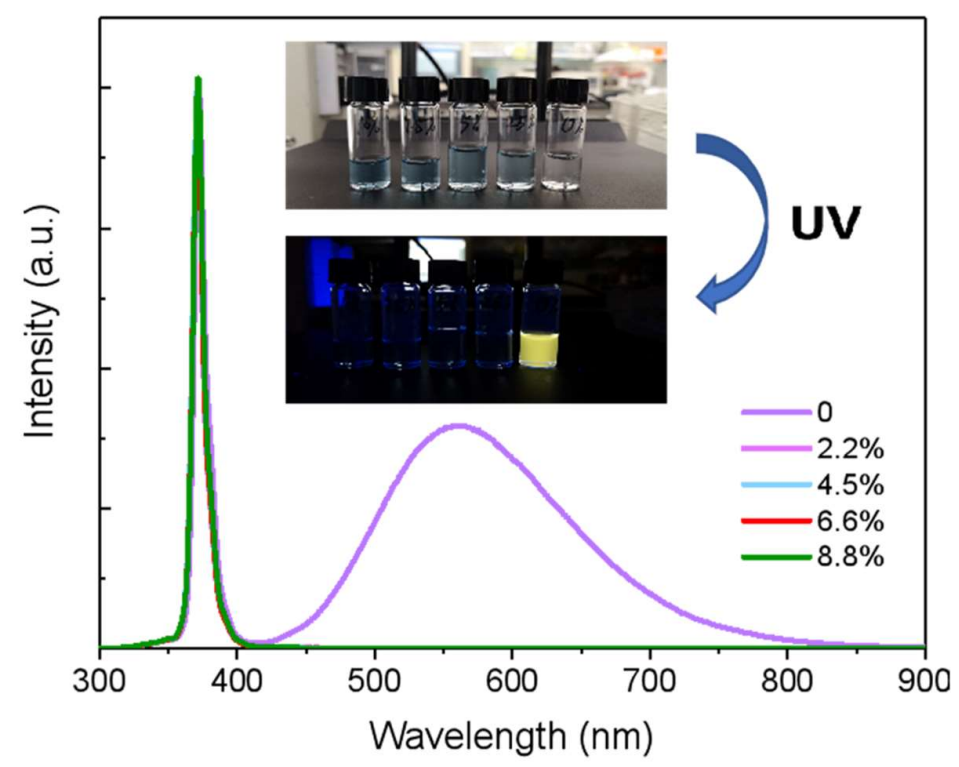

Figure S3. PL spectra of CZO NC solutions with different Co concentrations under $365 \mathrm{~nm}$ ultraviolet radiation. The insets are pictures of the five samples under ambient light (top) and ultraviolet light (bottom).

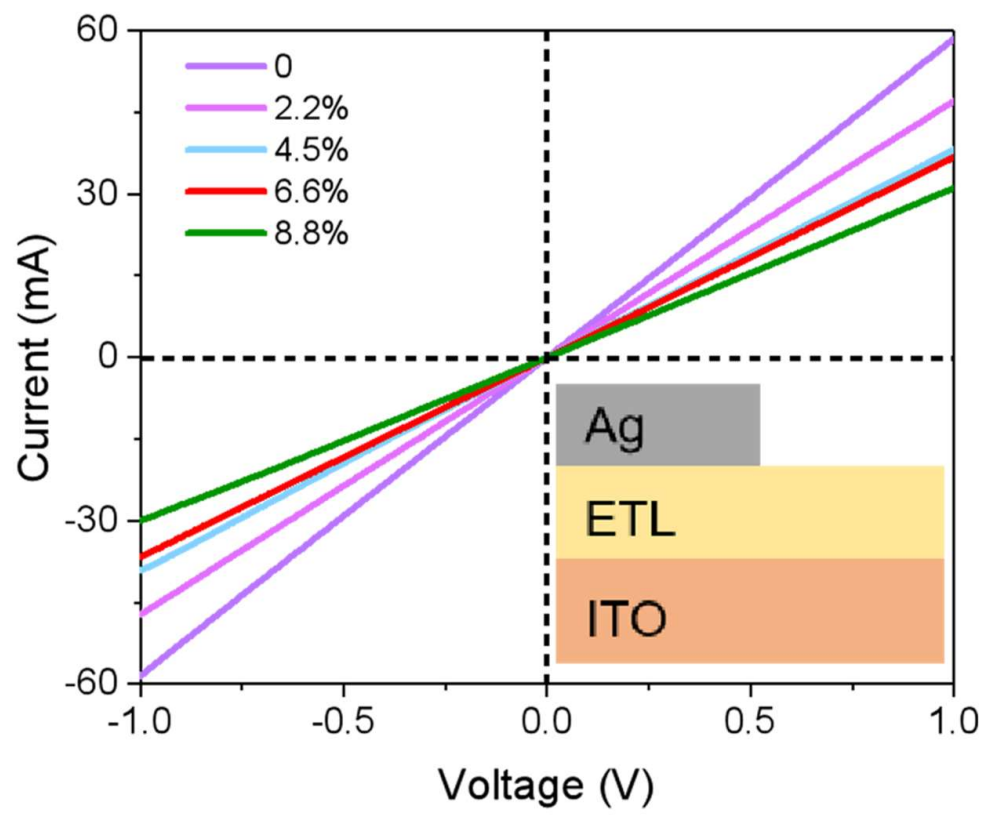

Figure S4. Current-voltage characteristics of ITO/CZO/Ag under applied voltage from -1.0 to $+1.0 \mathrm{~V}$. 

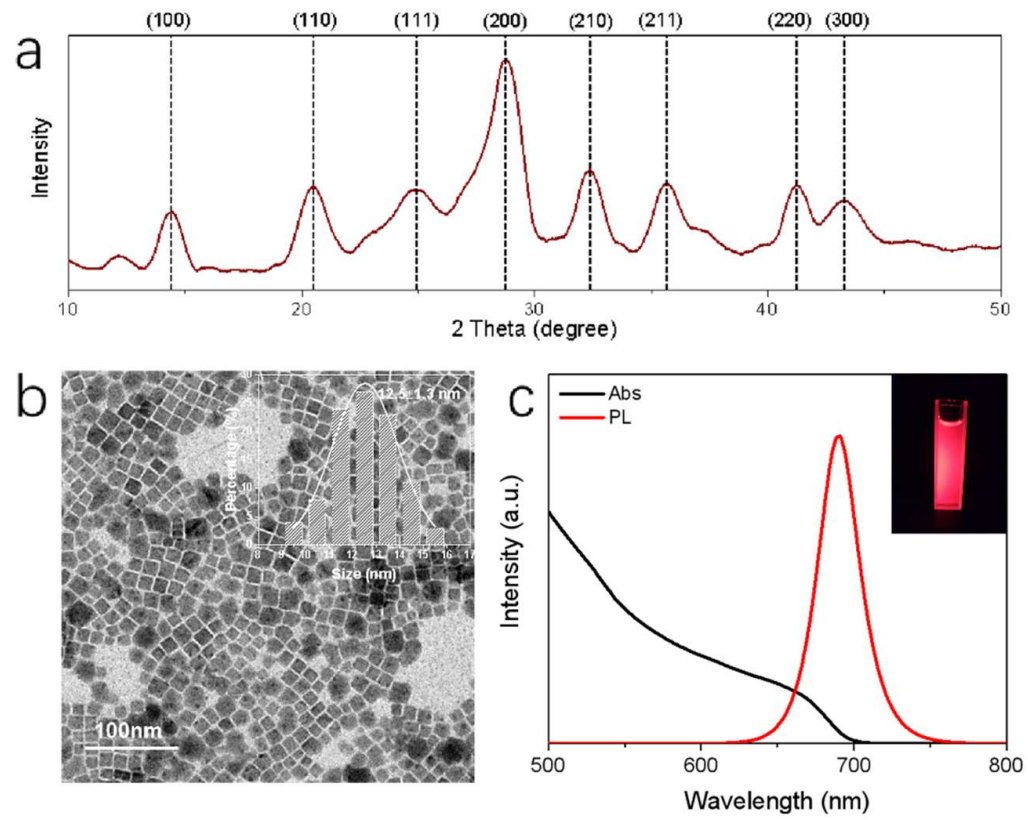

Figure S5. (a) XRD pattern, (b) TEM image, and (c) absorption and PL spectra of

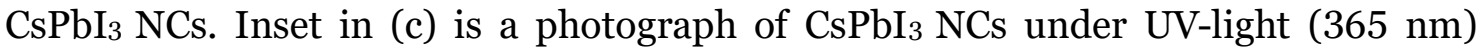
irradiation.
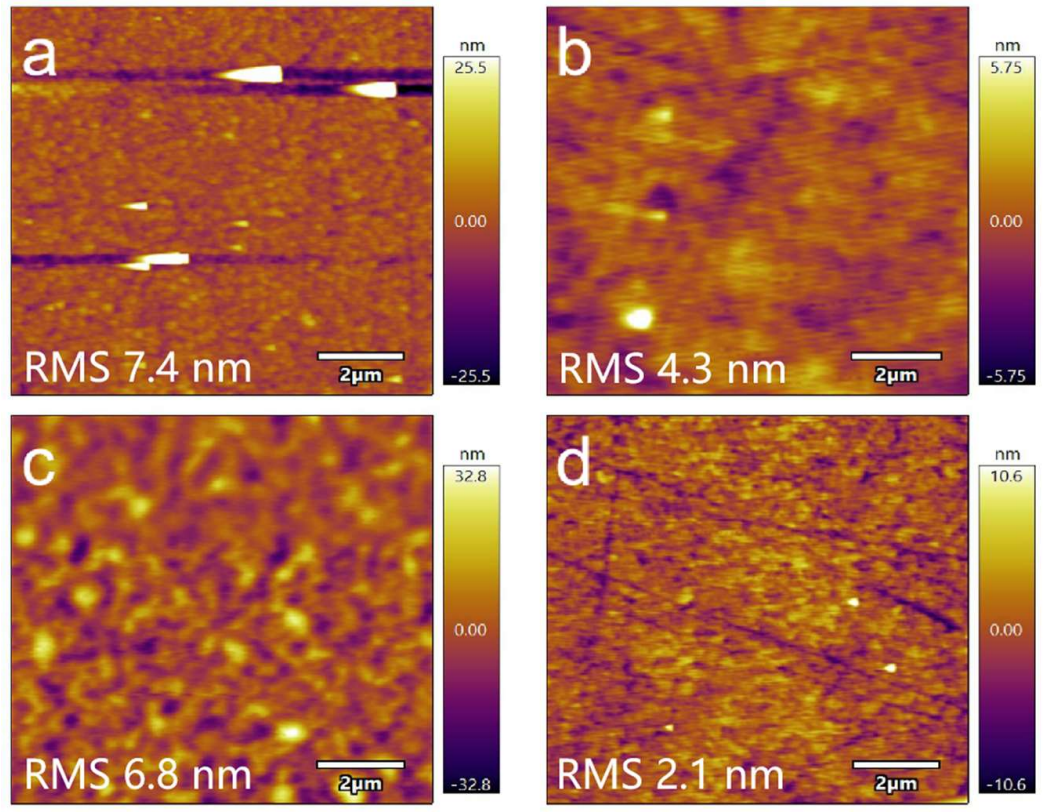

Figure S6. AFM images of (a) $\mathrm{ZnO}$ and (b) $\mathrm{CZO} \mathrm{NCs}$, and $\mathrm{CsPbI}_{3} \mathrm{NC}$ films deposited on (c) $\mathrm{ZnO}$ and (d) CZO. 


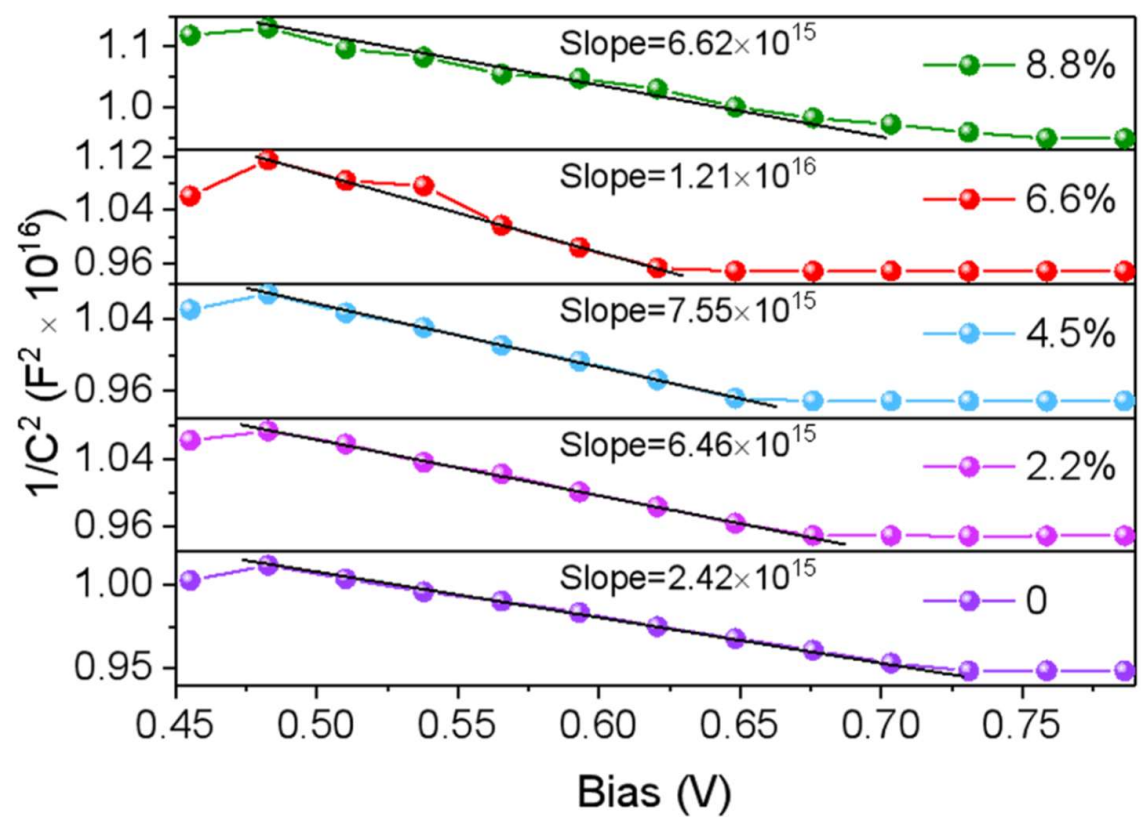

Figure S7. Mott-Schottky (M-S) plots of the LED with structure ITO/CoxZn1${ }_{x} \mathrm{O} / \mathrm{CsPb}_{3} / \mathrm{TCTA} / \mathrm{MoO}_{3} / \mathrm{Ag}$, where $\mathrm{x}=0,2.2 \%, 4.5 \%, 6.6 \%$, and $8.8 \%$.

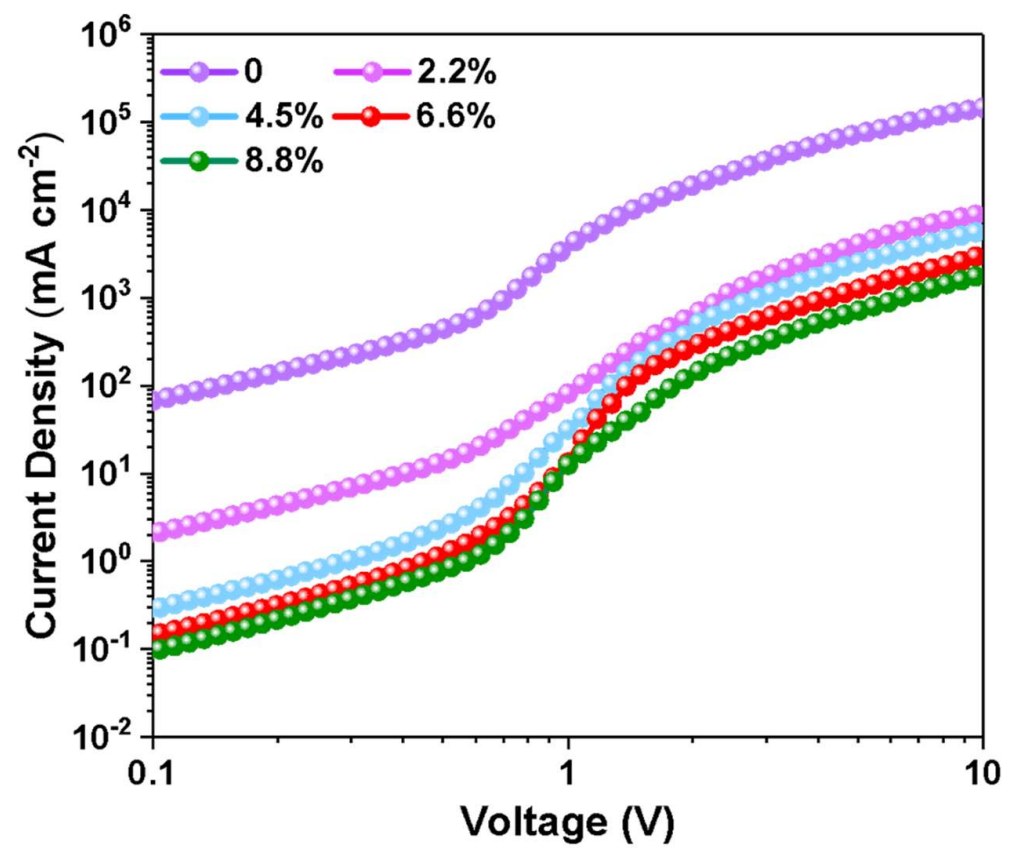

Figure S8. Current density-voltage characteristic curves of $\mathrm{ITO} / \mathrm{Zn}_{1-\mathrm{x}} \mathrm{Co}_{\mathrm{x}} \mathrm{O}(\mathrm{x}=0$, $2.2 \%, \quad 4.5 \%, \quad 6.6 \%, \quad$ and $8.8 \%) / \mathrm{CsPb}_{3} / \mathrm{Ag}$ electron-only and ITO/PEDOT:PSS/CsPbI3/TCTA/MoO3/Ag hole-only devices. 


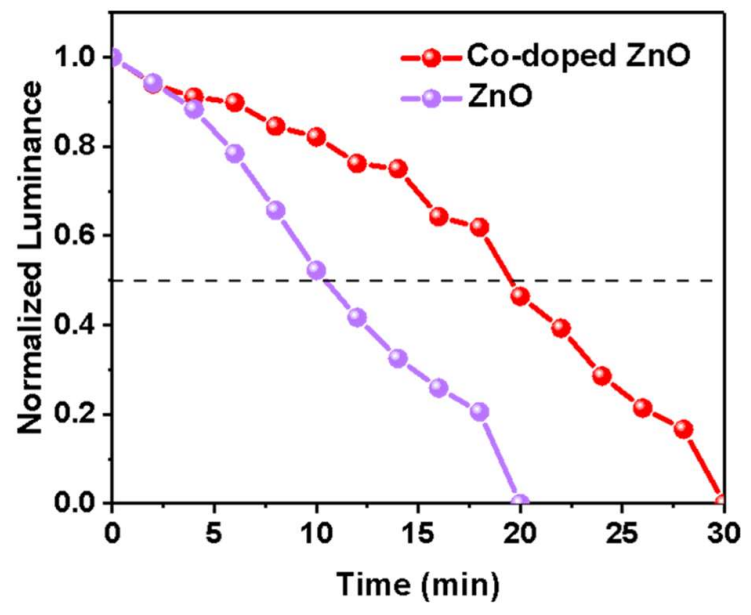

Figure S9. Stability tests for Co-doped ZnO-based and ZnO-based PNC LEDs under $3 \mathrm{~mA} \mathrm{~cm}^{-2}$.
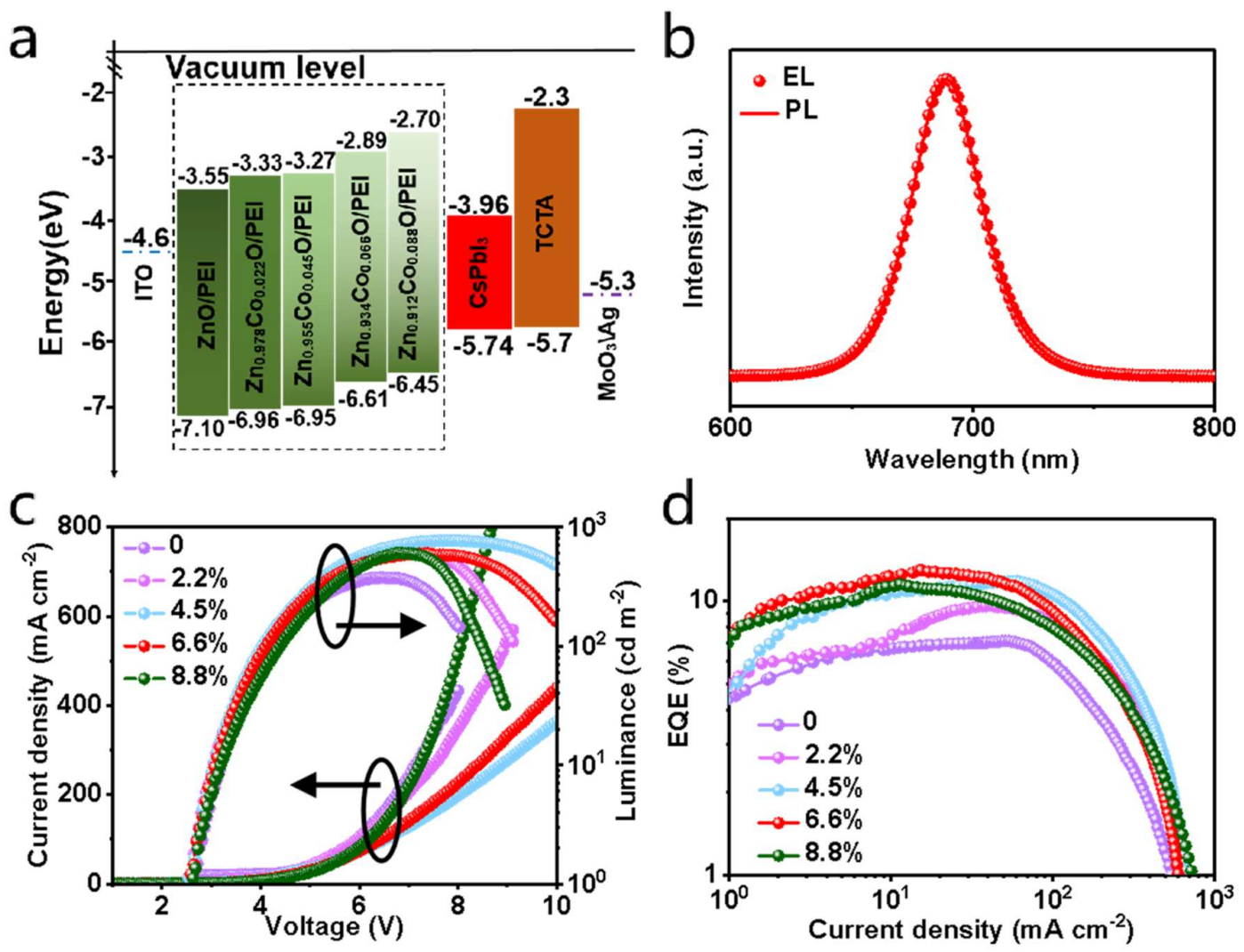

Figure S10. (a) Energy level band diagram of the CsPbI3 NC LEDs. (b) PL and EL patterns for $\mathrm{CsPbI}_{3} \mathrm{NC}$ LEDs. (c) Current density and luminance vs bias voltage ( $\mathrm{J}-\mathrm{V}$ $L$ ) and (d) EQE vs current density of these devices. 
Table S1. ICP-MS analyses of $\mathrm{Zn}_{1-\mathrm{x}} \mathrm{CO}_{\mathrm{x}} \mathrm{O} \mathrm{NCs}$

\begin{tabular}{|c|c|c|c|}
\hline \multirow{2}{*}{$\begin{array}{r}\text { Molar feed ratio of } \\
\mathrm{C}_{4} \mathrm{H}_{6} \mathrm{O}_{4} \mathrm{Co} \cdot 4 \mathrm{H}_{2} \mathrm{O}: \\
\left(\mathrm{C}_{4} \mathrm{H}_{6} \mathrm{O}_{4} \mathrm{Co} \cdot 4 \mathrm{H}_{2} \mathrm{O}\right. \\
\left.+\mathrm{C}_{4} \mathrm{H}_{6} \mathrm{O}_{4} \mathrm{Zn} \cdot 2 \mathrm{H}_{2} \mathrm{O}\right)\end{array}$} & \multicolumn{2}{|c|}{ Concentration (ppb) } & \multirow{2}{*}{$\begin{array}{c}\text { Molar } \\
\text { percentage of } \\
\mathrm{Co} /(\mathrm{Zn}+\mathrm{Co})(\%)\end{array}$} \\
\hline & Zn & Co & \\
\hline 0.025 & 115.974 & 2.331 & 2.2 \\
\hline 0.050 & 96.941 & 4.055 & 4.5 \\
\hline 0.075 & 99.241 & 6.102 & 6.6 \\
\hline 0.100 & 99.230 & 8.526 & 8.8 \\
\hline
\end{tabular}

Table S2 XRD scattering angles and lattice constants of $\mathrm{Zn}_{1-\mathrm{x}} \mathrm{CO}_{\mathrm{x}} \mathrm{O}$ NCs. $\theta, \beta$, and $\varepsilon$ represent Bragg angle, full half at maximum intensity of the diffraction line and lattice strain, respectively.

\begin{tabular}{c|c|c|c|c|c}
\hline Sample & 0 & $2.2 \%$ & $4.5 \%$ & $6.6 \%$ & $8.8 \%$ \\
\hline $\boldsymbol{\theta}$ (degree) & 34.44 & 34.07 & 33.98 & 33.85 & 33.60 \\
\hline $\boldsymbol{\beta}$ (degree) & 0.94 & 1.16 & 1.30 & 1.40 & 1.41 \\
\hline $\begin{array}{c}\text { Lattice constant } \\
(\boldsymbol{\AA})\end{array}$ & 2.60 & 2.62 & 2.64 & 2.65 & 2.67 \\
\hline $\boldsymbol{\varepsilon ( 1 0 - 3 )}$ & 3.38 & 4.19 & 4.70 & 5.07 & 5.12 \\
\hline
\end{tabular}


Table S3 Calculated electron mobilities $(\mu)$ and conductivities $(\sigma)$ of $\mathrm{Zn}_{1-\mathrm{x}} \mathrm{Co}_{\mathrm{x}} \mathrm{O}$ films

\begin{tabular}{c|c|c|c|c|c}
\hline Sample & 0 & $2.2 \%$ & $4.5 \%$ & $6.6 \%$ & $8.8 \%$ \\
\hline $\boldsymbol{\mu}\left(\times \mathbf{1 0}^{-3} \mathbf{c m}^{\mathbf{2}} \mathbf{V}^{-1} \mathbf{s}^{-1}\right)$ & 1.64 & 0.599 & 0.424 & 0.157 & 0.108 \\
\hline $\boldsymbol{\sigma}\left(\times \mathbf{1 0}^{-6} \mathbf{S ~ c m}^{-1}\right)$ & 7.23 & 5.90 & 4.87 & 4.62 & 3.90 \\
\hline
\end{tabular}

Table S4 Average PL lifetime $(<t>)$, PLQY, apparent nonradiative decay rate $\left(k_{n r}=\right.$ $\left.\frac{1-P L Q Y}{<t>}\right)$, and radiative decay rate $\left(k_{r}=\frac{P L Q Y}{<t>}\right)$ of $\mathrm{ITO} / \mathrm{CZO} / \mathrm{CsPbI} 3$

\begin{tabular}{c|c|c|c|c|c}
\hline Sample & 0 & $2.2 \%$ & $4.5 \%$ & $6.6 \%$ & $8.8 \%$ \\
\hline$<\mathbf{t}>\mathbf{( n s )}$ & 244 & 270 & 659 & 611 & 641 \\
\hline PLQY (\%) & 20.1 & 41.1 & 42.2 & 48.7 & 40.8 \\
\hline $\mathbf{k n r}\left(\times \mathbf{1 0}^{4} \mathbf{s}^{-1}\right)$ & 32.8 & 21.8 & 8.8 & 8.4 & 9.2 \\
\hline $\mathbf{k}_{\mathbf{r}}\left(\times \mathbf{1 0}^{4} \mathbf{s}^{-1}\right)$ & 8.2 & 15.2 & 6.4 & 8.0 & 6.4 \\
\hline
\end{tabular}

